\title{
Environmental Enrichment Increases Radiation-induced Apoptosis Not Spontaneous Apoptosis in Mouse Intestinal Crypt Cells
}

\author{
SHINYA YOKOMIZO ${ }^{1,2}$, MAYUMI NISHIMURA $^{1}$, TAKAMITSU MORIOKA ${ }^{1}$, UTAKO ENZAKA $^{1}$, \\ CHIZURU TSURUOKA ${ }^{1}$, YI SHANG ${ }^{1}$, YUKIKO NISHIMURA ${ }^{1}$, KAZUMASA INOUE $^{2}$, MASAHIRO FUKUSHI ${ }^{2}$, \\ TATSUHIKO IMAOKA ${ }^{1,2}$, SHIZUKO KAKINUMA ${ }^{1,2}$ and YOSHIYA SHIMADA ${ }^{1,3}$ \\ ${ }^{1}$ Department of Radiation Effects Research, National Institute of Radiological Sciences, \\ National Institutes for Quantum Science and Technology (QST), Chiba, Japan; \\ ${ }^{2}$ Department of Radiological Science, Graduate School of Human Health Sciences, \\ Tokyo Metropolitan University, Tokyo, Japan; \\ ${ }^{3}$ Institute for Environmental Sciences, Aomori, Japan
}

\begin{abstract}
Background/Aim: An enriched environment (EE) modifies apoptotic cell death and promotes cell proliferation in the central nervous system (CNS) in mice. However, few studies have examined the effects of an EE on apoptosis in non-CNS organs in model orgamisms. In addition, the intestinal tract is one of organs at high-risk of carcinogenesis after radiation exposure. Herein we evaluated the effects of an EE on spontaneous and radiation-induced apoptosis in intestinal crypt cells of mice. Materials and Methods: Juvenile (3-week-old) and adult (11-week-old) male B6C3F 1 mice were housed in a standard environment or EE for 8 weeks and then were whole-body irradiated with 2 Gy X-rays. Apoptosis in the small intestine and colon was analyzed with antibody against cleaved caspase 3. Results: The EE significantly reduced body weight; adipose tissue weight; and serum levels of total cholesterol, triglyceride, leptin, and insulin. Although EE did not change the spontaneous apoptotic index without irradiation, it significantly increased the index after irradiation in the colonic crypt. The apoptotic
\end{abstract}

This article is freely accessible online.

Correspondence to: Yoshiya Shimada, Ph.D., Institute for Environmental Sciences, 1-7 Ienomae, Obuchi, Rokkasho-mura, Aomori 039-3212, Japan. Tel: +81 175711200, Fax: +81 175723690, e-mail: shimada.yoshiya@ies.or.jp and Takamitsu Morioka, Ph.D., Department of Radiation Effects Research, National Institute of Radiological Sciences, National Institutes for Quantum Science and Technology, 4-9-1 Anagawa, Inage-ku, Chiba 263-8555, Japan. Tel: +81 432064053, Fax: +81 432064138, e-mail: morioka.takamitsu@qst.go.jp

Key Words: Enriched environment, radiation, apoptosis, intestinal tract. index in the small intestinal crypt showed similar patterns. Conclusion: An EE enhances radiation-induced apoptosis of stem/progenitor cells in the small intestine and colon without affecting spontaneous apoptosis. An EE may thus reduce the risk of cancer in the intestinal tract after radiation exposure such as radiotherapy.

An enriched environment (EE) refers to an animal housing condition that provides physical, psychological, cognitive, and social stimulation (1). In this environment, animals are housed in much larger cages than conventional ones, and items of various shape, colour, size, and texture are used for sensory-motor and social stimulation $(1,2)$. As a result, an EE offers opportunities for animals to perform a repertoire of species-specific behaviors by integrating multiple sensory experiences (1). Thus, an EE is considered to be a 'eustress', which induces health-promoting or adaptive physiological responses in animals (3). It has been proposed that an EE significantly affects functions of the central nervous system (CNS) such as neurogenesis, plasticity, learning, and memory (4). Little is known, however, on the effects of an EE on other organs.

Apoptosis is the process of programmed cell death and is an important mechanism for regulating the development and homeostasis of various organs and for eliminating damaged cells (5). One of the effects of an EE on the CNS is the inhibition of apoptosis. For example, an EE decreases spontaneous apoptosis in the granule cells of the hippocampus in male rats (6). In addition, an EE attenuates sevoflurane- and ketamine-induced neuronal apoptosis $(7,8)$. The inhibitory effects on neuronal apoptosis may contribute to improved learning and memory and disease prevention (9). Recently, Li et al. reported that an EE attenuates 
ketamine-induced apoptosis, but not spontaneous apoptosis, in the rat heart and kidney (10). However, there have been few additional studies that have focused on the effects of an EE on apoptosis in organs outside the CNS.

In contrast to neuronal cells, intestinal crypt cells actively proliferate and thus are highly sensitive to ionizing radiationinduced apoptosis. The apoptosis of intestinal crypt cells has been extensively studied in radiation biology (11-15). Recently, it was shown that radiation-induced apoptosis on several organs is modified by lifestyle factors including diet and environmental conditions (16-18). In this study, we examined the effects of an EE on the apoptosis of intestinal crypt cells in mice after irradiation. We found that an EE enhanced radiation-induced apoptosis, but not spontaneous apoptosis, in both the small intestine and colon.

\section{Materials and Methods}

Mice. As the effects of an EE depend on the age at which the EE is introduced $(19,20)$, we used both juvenile and adult mice. Threeweek-old male $\mathrm{B} 6 \mathrm{C} 3 \mathrm{~F} 1$ hybrid mice (resulting from a cross between female $\mathrm{C} 57 \mathrm{BL} / 6 \mathrm{NCrl}$ mice and male $\mathrm{C} 3 \mathrm{H} / \mathrm{HeNCrl}$ mice) were purchased from Charles River Laboratories (Kanagawa, Japan). All animal experiments were approved by the Institutional Animal Care and Use Committee of the National Institutes for Quantum Science and Technology and conducted under related guidelines (Approval No. 16-1008). The welfare of animals at the institution was reviewed by an external program of the Japanese Association of Laboratory Animal Facilities of National University Corporations and the Japanese Association of Laboratory Animal Facilities of Public and Private Universities.

Housing conditions. We previously reported our established EE condition $(21,22)$. Briefly, an EE was created in a large cage (depth, $542 \mathrm{~mm}$; width, $426 \mathrm{~mm}$; height, $200 \mathrm{~mm}$ ) supplemented with a running wheel, igloo, paper-based nest box, tunnel, red transparent plastic nest box, wooden block, and nesting sheet (Bio-Serv, Frenchtown, NJ, USA) as shown in Figure 1A. Each item was randomly positioned, and all items were re-positioned weekly to maintain novelty. A standard environment (SE) was created in a standard laboratory cage $(300 \mathrm{~mm} \times 170 \mathrm{~mm} \times 100 \mathrm{~mm})$ without any supplements (Figure 1A). In both conditions, cages had woodchip bedding that was changed weekly. All mice were housed in groups of five mice per cage on a 12 -h light/12-h dark cycle at $23 \pm 2^{\circ} \mathrm{C}$ and $50 \pm 10 \%$ humidity. They were provided a standard laboratory diet (MB-1; Funabashi Farm Co., Ltd., Chiba, Japan) and water ad libitum.

Irradiation. Irradiation was performed using a Pantak HF-320 Xray generator (Pantak Ltd., East Haven, CT, USA). After being reared under SE or EE conditions for 8 weeks, mice were wholebody irradiated with $2 \mathrm{~Gy}$ at a dose rate of $0.6 \mathrm{~Gy} / \mathrm{min}(200 \mathrm{kVp}$, $20 \mathrm{~mA}$, with a filter composed of 0.5 -mm-thick copper and aluminium plates) as reported (15). Non-irradiated mice were handled similarly on the day of irradiation.

Experimental design. We set up two experiments (Figure 1B), one to characterize the effects of the EE condition (Experiment 1) and the other to analyse apoptosis (Experiment 2). All mice were
A

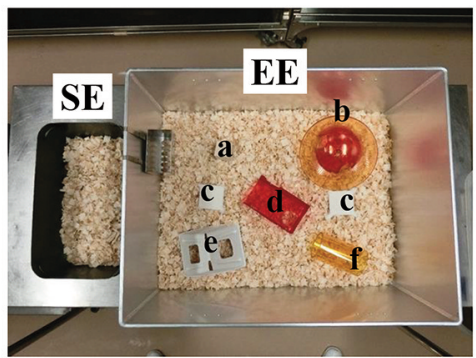

B
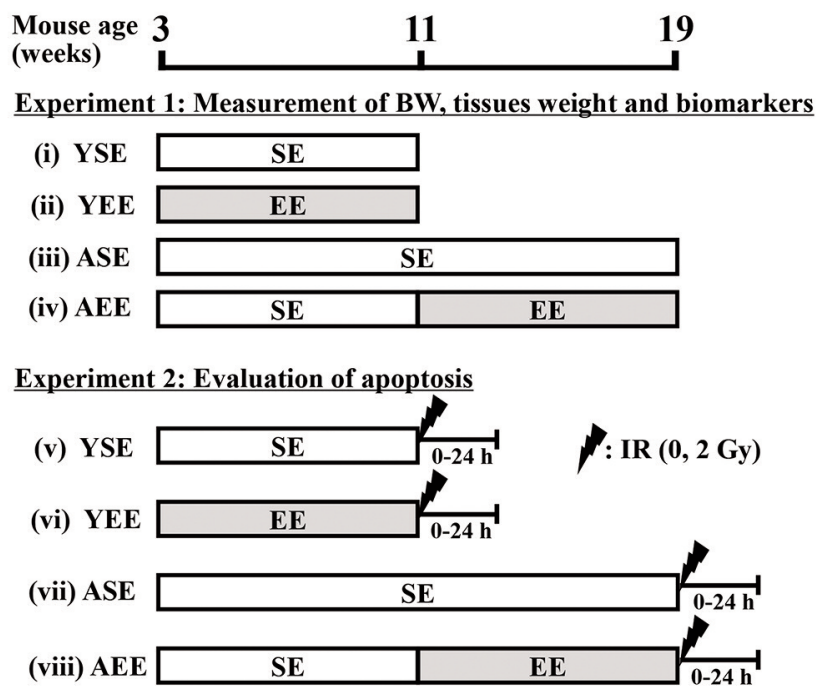

Figure 1. The enriched environment (EE) and experimental design. (A) Setup of the standard environment (SE) and EE. a, wooden block; b, running wheel with igloo; $c$, nesting sheet; $d$, red transparent plastic nest box; e, paper-based nest box; $f$, tunnel. (B) Three-week-old (young, $Y)$ or 11-week-old (adult, A) mice were housed for 8 weeks in a SE or EE and then were irradiated (IR) with 0 or 2 Gy. Mice were assayed humanely from 0 (unirradiated) to $24 \mathrm{~h}$ after irradiation.

weighed weekly during the experimental period. In Experiment 1, juvenile mice were divided after weaning into the following four groups (i-iv): (i) mice housed in SE cages from 3 to 11 weeks of age (i.e., through postnatal development until young adulthood; YSE group); (ii) mice housed in EE cages from 3 to 11 weeks of age (YEE group); (iii) mice housed in SE cages from 3 to 11 weeks of age and then, as adults, kept therein until 19 weeks of age (i.e., during adulthood; ASE group); and (iv) mice housed in SE cages from 3 to 11 weeks of age and then, as adults, transferred to EE cages and housed therein from 11 to 19 weeks of age (AEE group). All mice were euthanized by cardiac puncture under isoflurane anaesthesia, and blood was collected for the biochemical analysis of lipid metabolism, adipokines, and insulin. Epididymal white adipose tissue (WAT) and interscapular brown adipose tissue (BAT) were removed to determine their weights, and the latter was fixed in $10 \%$ neutral-buffered formalin overnight, followed by preparation of paraffin-embedded sections for histopathological and immunohistochemical analyses. 
In Experiment 2, mice were divided into four groups (v-viii) as in Experiment 1 and then were sham-irradiated $(0 \mathrm{~Gy})$ or irradiated ( 2 Gy) at 11 or 19 weeks of age. The housing conditions and means of euthanasia were the same as in Experiment 1. After euthanasia, the small intestine and colon were removed, rinsed in ice-cold phosphate-buffered saline, opened longitudinally, rolled with the mucosa outwards, and then paraffin-embedded sections were prepared by the same method as BAT for the evaluation of apoptosis using immunohistochemistry.

Immunohistochemistry. For staining with an antibody against cleaved caspase 3, 3- to 4- $\mu \mathrm{m}$-thick sections were stained using the Ventana Benchmark Ultra system (Ventana, Tucson, AZ, USA). Deparaffinization was performed using EZ prep solution (Ventana). For antigen retrieval, sections were incubated in Cell Conditioning 1 solution (Ventana) containing Tris/borate/ethylenediaminetetraacetic acid $(\mathrm{pH} 7.8)$ at $93^{\circ} \mathrm{C}$ for $32 \mathrm{~min}$. To block protein-binding sites, sections were then incubated with $10 \%$ (v/v) goat serum in Protein Block Serum-Free solution (Dako, Japan Inc., Tokyo Japan) for 16 min and were treated with an endogenous biotin blocking kit (Ventana). A rabbit polyclonal primary antibody against cleaved caspase 3 (1:800 dilution; Cell Signaling Technology, Danvers, MA, USA) was incubated with the sections at $37^{\circ} \mathrm{C}$ for $28 \mathrm{~min}$. Endogenous peroxides were quenched using $3 \% \mathrm{H}_{2} \mathrm{O}_{2}$ reagent (Ventana) at $37^{\circ} \mathrm{C}$ for $4 \mathrm{~min}$. Biotin-labelled goat anti-rabbit $\operatorname{IgG}$ (1:200; Jackson ImmunoResearch Laboratories, West Grove, PA, USA) was incubated with the sections at $37^{\circ} \mathrm{C}$ for $16 \mathrm{~min}$. Antigen sites were then visualized with Discovery DAB Map Detection Kit (Ventana). The sections were counterstained with hematoxylin.

Uncoupling protein 1 (UCP1) expression in adipose tissues was determined by manual immunohistochemical staining using 3- to 4- $\mu$ m-thick sections as follows. After deparaffinization, endogenous peroxidase activity was blocked by incubation with $0.3 \%(\mathrm{w} / \mathrm{v})$ hydrogen peroxide in methanol for $30 \mathrm{~min}$. As a pretreatment, antigen retrieval was performed by autoclaving (Decloaking Chamber Nxgen; Biocare, Concord, CA, USA) in $0.01 \mathrm{M}$ sodium citrate buffer $(\mathrm{pH} 6.0)$ at $110^{\circ} \mathrm{C}$ for $20 \mathrm{~min}$. Sections were blocked in $10 \%(\mathrm{v} / \mathrm{v})$ goat serum for $30 \mathrm{~min}$ at room temperature and incubated with rabbit polyclonal anti-UCP1 (1:100; ab10983; Abcam, Cambridge, UK) at $4^{\circ} \mathrm{C}$ overnight. Peroxidase-conjugated anti-rabbit $\operatorname{IgG}$ secondary antibodies (Histofine Simple Stain MAX PO(R); Nichirei Bioscience, Tokyo, Japan) were applied, and immunoreactivity was visualized with diaminobenzidine staining (DAB Substrate Kit; Vector Laboratories, Burlingame, CA, USA). Sections were counterstained with hematoxylin. All stained specimens were digitally stored in a J-SHARE archive (Japan Storehouse of Animal Radiobiology Experiments) for pathological and immunohistochemical analyses (23).

Serum assessment. Blood samples were collected at 11 (YSE and YEE) or 19 (ASE and AEE) weeks of age on experimental 1 (Figure 1B). Serum samples were obtained by centrifugation of clotted blood samples at $1,500 \times g$ for $10 \mathrm{~min}$ and stored at $-80^{\circ} \mathrm{C}$ until subsequent use. Total cholesterol (T-Cho; L-type Wako CHO-M kit; Wako Pure Chemical Industries, Ltd., Osaka, Japan) and triglyceride (TG; L-type Wako Triglyceride M kit; Wako Pure Chemical Industries, Ltd.) levels were measured at Nagahama Life Science Laboratory (Shiga, Japan). Leptin, adiponectin, insulin, IL-6 (interleukin-6), and MCP1 (monocyte chemotactic protein 1) levels were measured by microsphere-based immunoassays (Luminex xMAP kits, Luminex Co., Austin, TX, USA). Corticosterone levels were measured with an enzyme-linked immunosorbent assay kit (No. 501320; Cayman, Ann Arbor, MI, USA). Each sample was measured twice, and the resulting mean value was used for statistical analysis.

Detection and evaluation of apoptotic cells. Apoptotic cells were identified based on being positive for cleaved caspase 3 staining. We adopted two ways to quantify the extent of apoptosis for evaluation of time-dependent alterations and distribution patterns: 1) the percentage of crypts containing one or more apoptotic cells among all crypts in the section (hereafter, apoptotic index) and 2) the percentage of apoptotic cells among all cells in a specified cell position, as previously described (15). Apoptotic cells were counted only in sections of crypts that had a longitudinally continuous structure from the base to the crypt-villus junction. To score apoptosis, 50-211 small intestinal and 90-203 colonic crypts per mouse and at least 20 cells per each crypt were evaluated. All scoring was conducted in a blinded fashion.

Statistics. Data are expressed as the mean \pm standard deviation (SD) or standard error (SE). Welch's or Student's $t$-test was used to evaluate the differences between two groups based on the results of the $F$-test. A repeated-measures two-way analysis of variance was used to analyse changes in body weight (BW) over time between YSE and YEE and between ASE and AEE groups.

\section{Results}

Effect of EE housing during different ages on $B W$ and adipose tissues. We first characterized the EE condition used in our study by examining whether it changed physiological parameters of mice such as BW and adipose tissue weights in a manner consistent with a previous report (24). BW, which was determined every other week at about 10:00 am, increased during postnatal development in all groups, but the increase was smaller in YEE mice than in YSE mice $(p<0.01$, Figure $2 \mathrm{~A})$. The BWs of ASE mice increased from 11 to 19 weeks of age, whereas those of AEE mice did not increase, and the difference between the groups was significant $(p<0.01$, Figure 2B). The WAT and BAT weights were much smaller in YEE mice than in YSE mice; similarly, their weights in AEE mice were smaller than those in ASE mice $(p<0.01$, Table I). The reduction was much larger in WAT than BAT (70\% vs. 50\% reduction). Hematoxylin and eosin (HE) staining showed that the BAT adipocytes of YEE mice were smaller than those of YSE mice, which was most likely due to the decrease in lipid accumulation (Figure 2C and D). Immunohistochemically, expression of UCP1 in the BAT adipocytes of YEE mice was higher than in those of YSE mice (Figure 2C and D). As UCP1 has a role in thermogenesis (24), these results suggest that the EE condition reduces BW and adipose tissue weights through energy expenditure by UCP1mediated thermogenesis. 
A
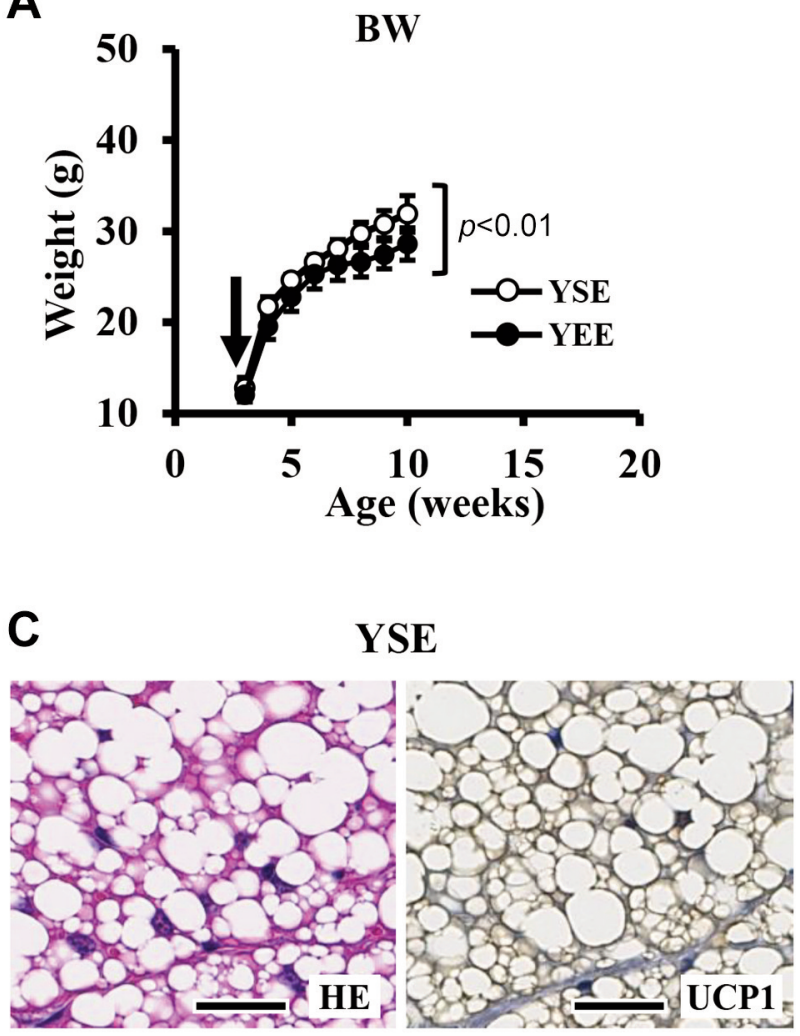

E

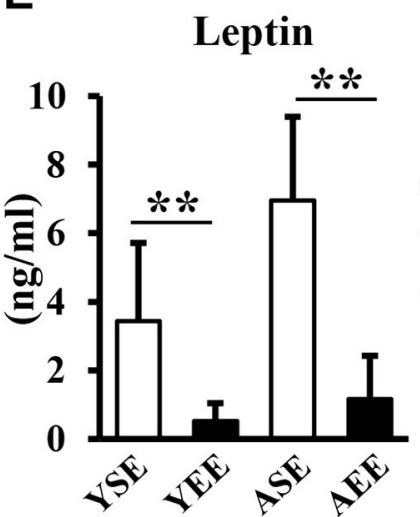

F Adiponectin

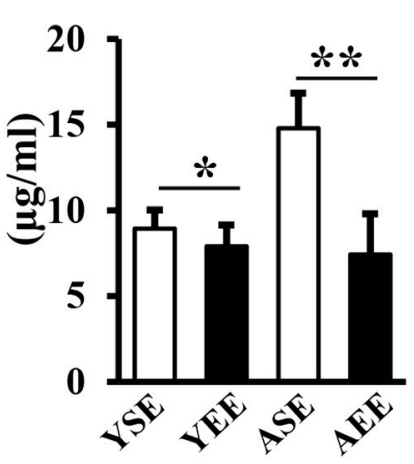

B

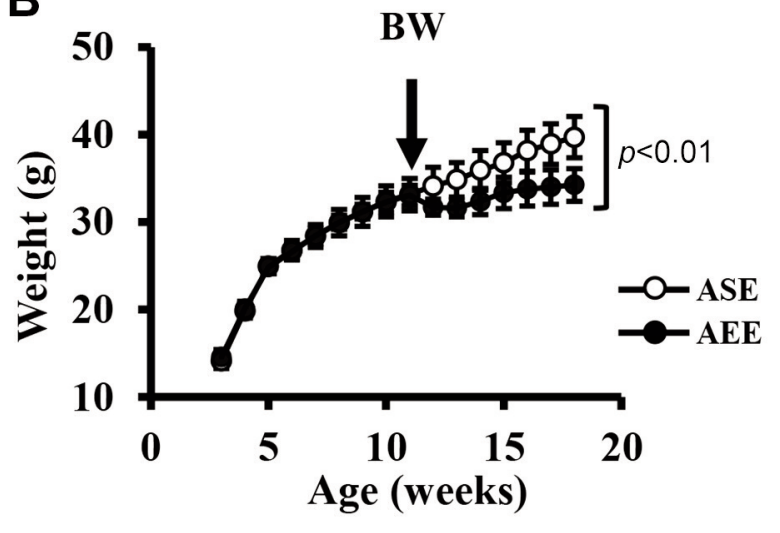

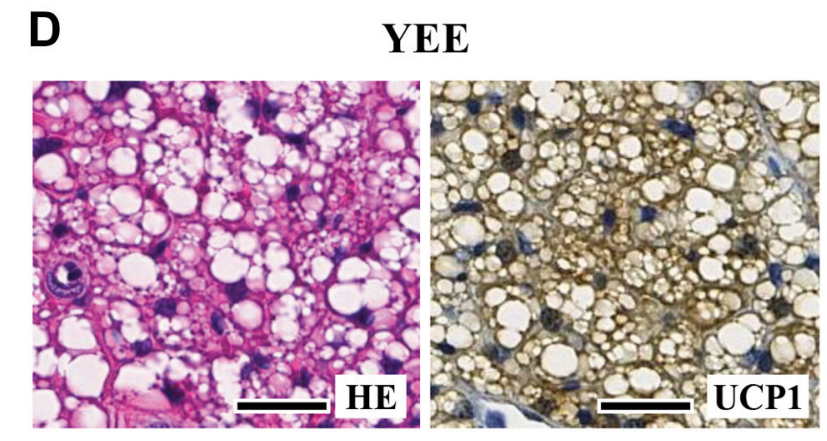

G

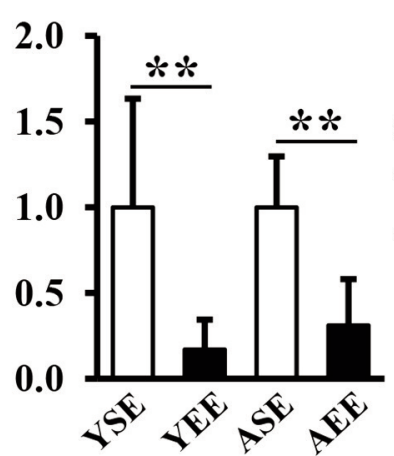

H

L/A ratio

Insulin

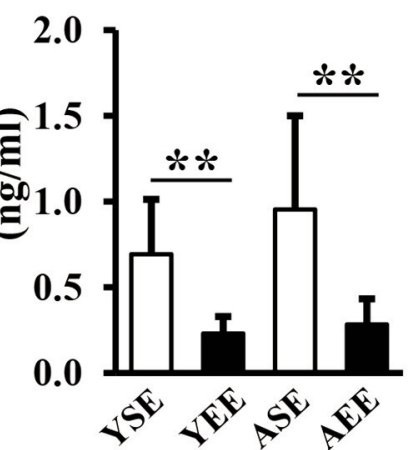

Figure 2. Effects of an enriched environment (EE) on body weight, brown adipose tissue, and serum hormone levels. (A and B) Body weights (BW) of mice exposed to an EE while young (A) or as adults (B). Arrows indicate the time at which half of the mice were shifted to an EE. (C and D) Histological and immunohistochemical features of brown adipose tissue in a YSE (C) and YEE (D) mouse. HE, hematoxylin and eosin; UCP1, uncoupling protein 1. Scale bars, $20 \mathrm{~mm}$. E-H: Quantification of leptin $(E)$, adiponectin $(F)$, the leptin/adiponectin $(L / A)$ ratio $(G)$, and insulin $(H)$ in serum samples from these mice is shown. Data are shown as the mean $\pm S D(n=15$ mice per group). Differences in body weight between the two groups were analyzed by a repeated measures two-way analysis of variance. ${ }^{*} p<0.05, * * p<0.01$.

Effect of EE housing during different age periods on serum lipids, adipokines, and insulin. A previous study indicated that EE affects lipid components and hormones generated from adipose tissue (24). Our EE housing also significantly decreased serum levels of T-Cho and TG $(p<0.01$, Table I). Furthermore, both the YEE and AEE groups showed 
Table I. Summary of adipose tissue weights ${ }^{a}$ and serum biomarkers ${ }^{b}$.

\begin{tabular}{|c|c|c|c|c|}
\hline \multirow[b]{2}{*}{ Tissue } & \multicolumn{2}{|c|}{ Young (3-11 weeks old) } & \multicolumn{2}{|c|}{ Adult (11-19 weeks old) } \\
\hline & YSE & YEE & ASE & AEE \\
\hline WAT (mg) & $690 \pm 260$ & $190 \pm 88 *$ & $1,500 \pm 310$ & $350 \pm 220 *$ \\
\hline BAT (mg) & $120 \pm 34$ & $63 \pm 13^{*}$ & $150 \pm 22$ & $75 \pm 16^{*}$ \\
\hline Biomarker & YSE & YEE & ASE & AEE \\
\hline T-Cho $(\mathrm{mg} / \mathrm{ml})$ & $100 \pm 11$ & $73 \pm 6.0 *$ & $110 \pm 7.7$ & $80 \pm 12 *$ \\
\hline $\mathrm{TG}(\mathrm{mg} / \mathrm{ml})$ & $120 \pm 31$ & $81 \pm 29 *$ & $140 \pm 50$ & $81 \pm 36^{*}$ \\
\hline CORT (ng/ml) & $74 \pm 23$ & $88 \pm 15$ & $73 \pm 14$ & $55 \pm 31$ \\
\hline
\end{tabular}

YSE, Young (Y) mice housed in standard environment (SE); YEE, young mice housed in an environmental enrichment (EE); ASE, adult (A) mice housed in a SE; AEE, adult mice housed in an EE; WAT, white adipose tissue; BAT, brown adipose tissue; T-Cho, total cholesterol; TG triglyceride; CORT, corticosterone. ${ }^{*} p<0.01 v s$. corresponding SE group. aValues are the mean $\pm S D(n=15)$; bvalues are the mean $\pm S D(n=5-10)$.

significantly reduced serum levels of leptin, a hormone released from adipose tissue with accumulated lipid, compared to the corresponding SE groups $(p<0.01$, Figure $2 \mathrm{E})$. Adiponectin, which is released from adipose tissue with minimal lipid accumulation, was also significantly reduced in both the YEE and AEE groups relative to their respective SE controls $(p<0.05$, Figure $2 \mathrm{~F})$. In addition, the leptin/adiponectin (L/A) ratio, which reflects the balance of the two adipose hormones, was significantly smaller in the YEE and AEE groups compared to the YSE and ASE groups, respectively $(p<0.01$, Figure $2 \mathrm{G})$. A reduced L/A ratio indicates that metabolism is directed towards suppression of lipid accumulation (25). The YEE and AEE groups also showed significantly reduced serum levels of insulin as compared with the YSE and ASE groups, respectively ( $p<0.01$, Figure $2 \mathrm{H}$ ). Our EE condition thus reduced serum levels of lipids and adipose tissue-derived cytokines, regardless of the age at which mice were exposed to the EE, which is consistent with previous findings $(20,24,26)$. Taken together, these results indicate that our EE rearing conditions modified energy metabolism and the relevant endocrine system. In contrast, the level of corticosterone, a major stress hormone, was not significantly changed by the EE housing (Table I). In addition, serum levels of the inflammatory cytokines IL- 6 and MCP1 stayed below the limit of detection for the most part and were not significantly different between the YSE and YEE groups or between the ASE and AEE groups (data not shown), indicating that our EE system did not affect basal levels of inflammatory cytokines, in contrast to the effects of slightly different EE conditions reported previously (27-29).

Spontaneous and radiation-induced apoptosis in the crypt cells of the small intestine and colon. Apoptotic cells in the small intestine and colon were detected by immunohistochemical staining using an antibody against cleaved caspase 3. Apoptotic cells were mainly distributed in crypts, and the number of apoptotic cells was increased under the EE condition (Figure $3 \mathrm{~A}$ and $\mathrm{B}$ ). We next evaluated time-dependent alterations in the apoptotic index after radiation exposure (Figure 3C and D). The apoptotic indices in crypt cells of both the small intestine and colon reached a peak at $3 \mathrm{~h}$ after irradiation (Figure $3 \mathrm{C}$ and D; $\mathrm{n}=2$ or 3 mice per condition per time point) regardless of the $\mathrm{EE}$ housing, which is consistent with previous reports $(5,15)$. Thus, we evaluated the apoptotic index at $3 \mathrm{~h}$ after irradiation. To this end, we placed four or five mice in each group to minimize errors in the measured values.

We next examined the modifying effects of an EE on the apoptotic index in young mice (11 weeks of age). In mice in the absence of irradiation, the apoptotic indices of the small intestine and colon were similar between YSE and YEE mice

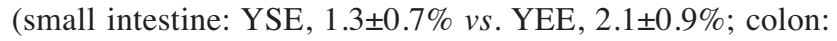
YSE, $2.0 \pm 1.6 \% v s$. YEE, $1.1 \pm 1.0 \%)$, indicating no effect of EE on spontaneous apoptosis (Figure $3 \mathrm{E}$ and F). In contrast, in irradiated mice, the apoptotic indices of the small intestine and colon were significantly elevated compared to the indices of non-irradiated mice (small intestine: YSE, $43 \pm 16 \%$ vs. YEE, $63 \pm 14 \%$; colon: YSE, 20 $\pm 7.0 \%$ vs. YEE, $48 \pm 4.0 \%$; Figure $3 \mathrm{E}$ and $\mathrm{F}$ ). Thus, the $\mathrm{EE}$ condition significantly increased the apoptotic index of the colon in irradiated mice compared to the SE condition $(p<0.01$, Figure 3F).

We also evaluated the apoptotic index in adult mice at 19 weeks of age. Without irradiation, an EE did not affect the apoptotic index of either the small intestine or colon (small intestine: ASE, $1.5 \pm 0.7 \% v s$. AEE, $1.8 \pm 1.0 \%$; colon: ASE, $1.4 \pm 0.7 \%$ vs. AEE, $2.0 \pm 0.8 \%$; Figure $3 \mathrm{E}$ and F). In irradiated mice, the apoptotic index of both the small intestine and colon was significantly increased relative to the index of non-irradiated mice (small intestine: ASE, 33 $\pm 3.5 \%$ vs. AEE, $42 \pm 6.0 \%$; colon: ASE, $17 \pm 2.0 \%$ vs. AEE, $31 \pm 7.0 \%$; Figure $3 \mathrm{E}$ and $\mathrm{F}$ ), and, moreover, these indices were significantly increased by EE (small intestine: ASE, 33 $\pm 3.5 \%$ vs. AEE, $42 \pm 6.0 \%$; colon: ASE, $17 \pm 2.0 \%$ vs. AEE, $31 \pm 7.0 \%$; Figure $3 \mathrm{E}$ and $\mathrm{F})$. Additionally, the effect of the $\mathrm{EE}$ tended to be greater in young mice than in adult mice. These results suggest that an EE enhances apoptosis induction after radiation exposure in the small intestine and colon.

We next evaluated the distribution of apoptotic cells in small intestinal and colonic crypts at $3 \mathrm{~h}$ after irradiation (Figure 4). Cells were numbered sequentially upwards, with those at the base of the crypt denoted as position 1 , as described (5). In irradiated mice of both the young and adult groups, the apoptotic cells were distributed most often at cell positions 3 and 4 in the small intestine and positions 1 and 2 in the colon, consistent with a previous study (30). In 
A
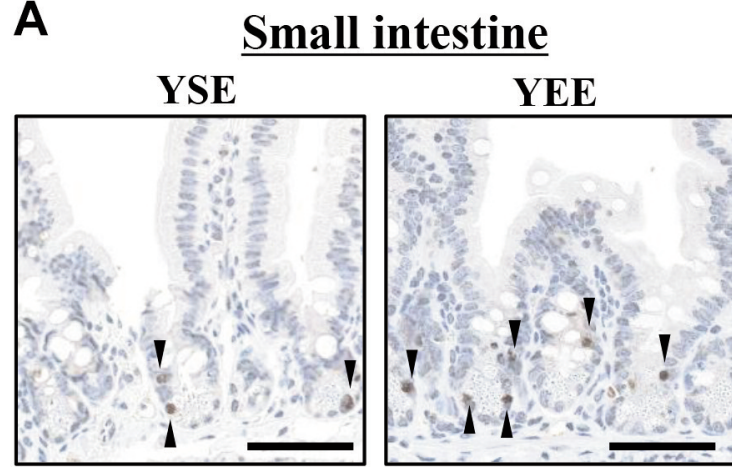

C

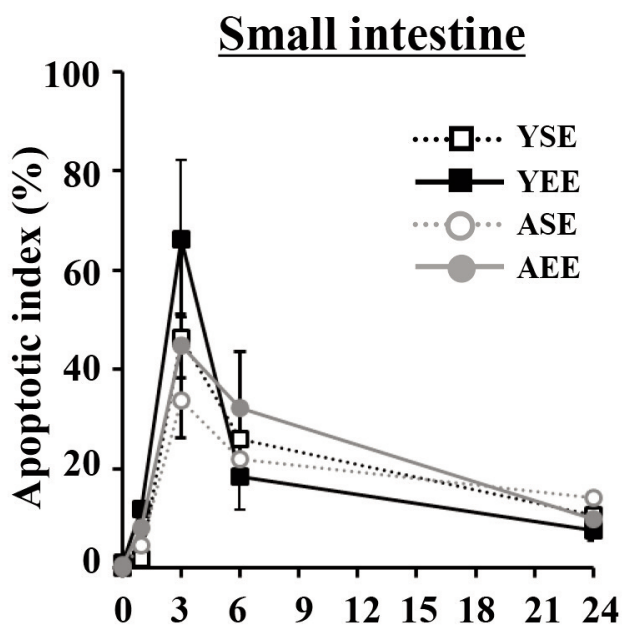

Time after irradiation (h)

E

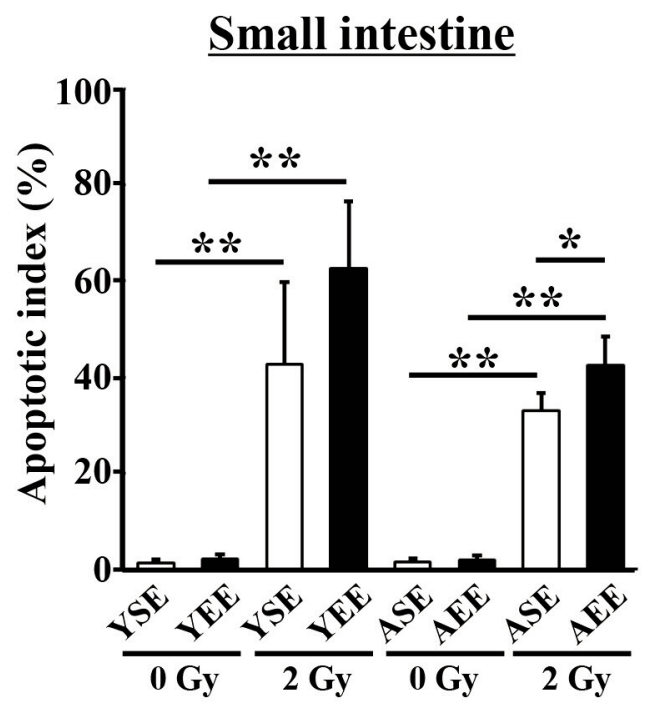

B

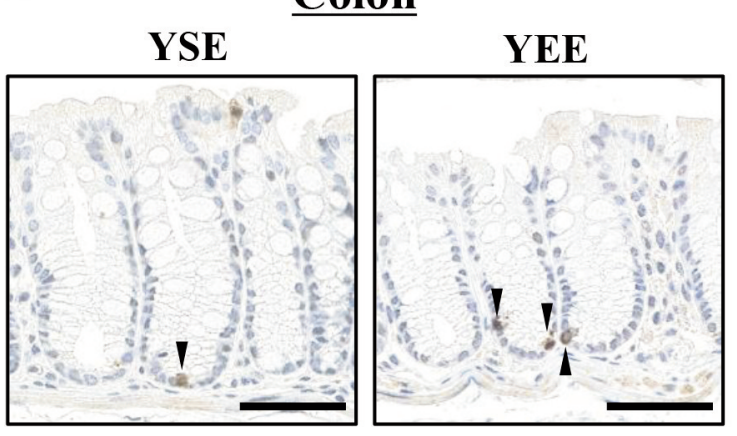

D

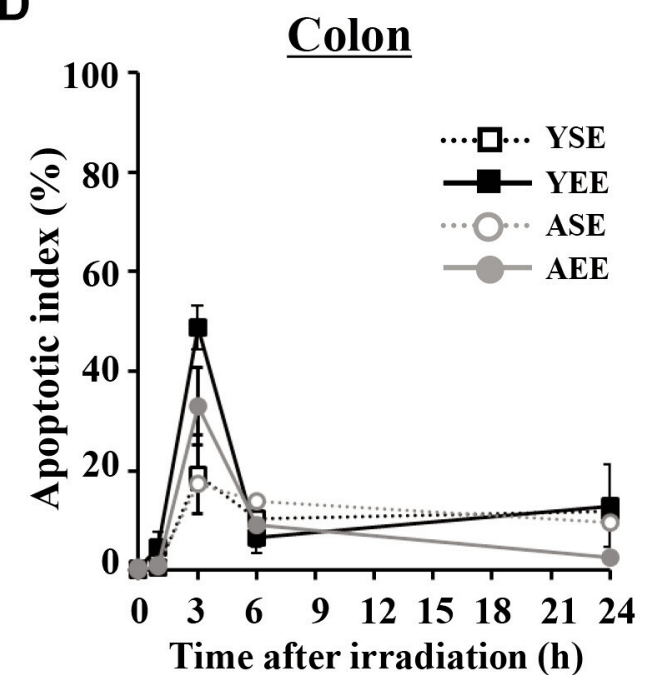

F
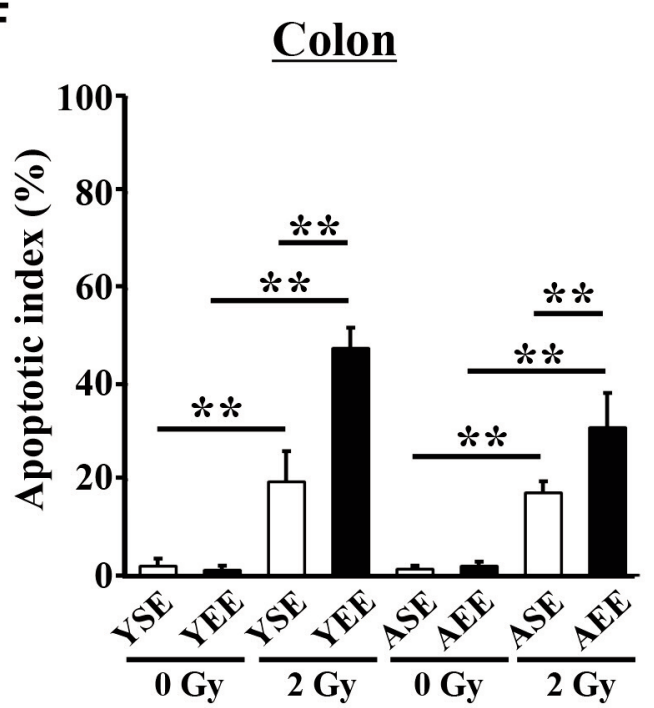

Figure 3. An enriched environment (EE) induces apoptosis in the small intestinal and colonic crypts after irradiation of young and adult mice. (A and B) Representative sections stained for cleaved caspase 3 from typical small intestinal (A) and colonic (B) crypts of irradiated YSE and YEE mice. Arrowheads indicate apoptotic cells. Scale bars represent $50 \mathrm{~mm}$. (C and D) Time course of the apoptotic index of the small intestine $(C)$ and colon (D) of irradiated young and adult mice that had been reared in a standard environment (SE) or an EE ( $n=2$ or 3 mice per group). (E and $F)$ Apoptotic index in the small intestine $(E)$ and colon $(F)$ of non-irradiated and irradiated mice at 3 h after irradiation ( $n=4$ or 5 mice per group). Data are shown as the mean $\pm S D . * p<0.05, * * p<0.01$. 
A

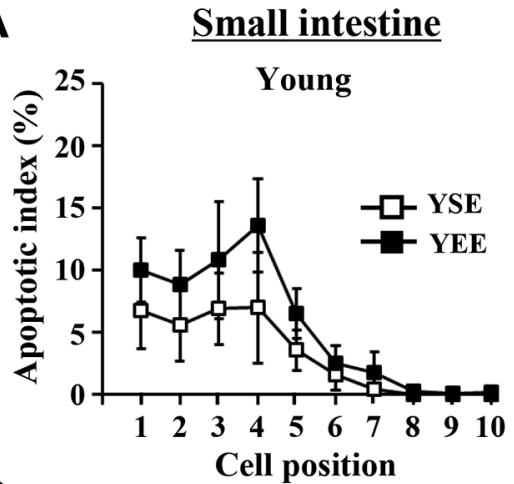

C

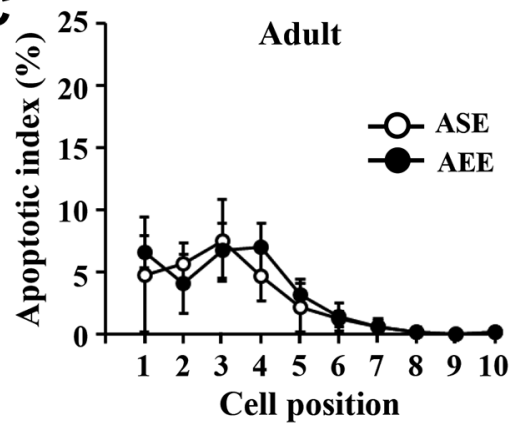

B

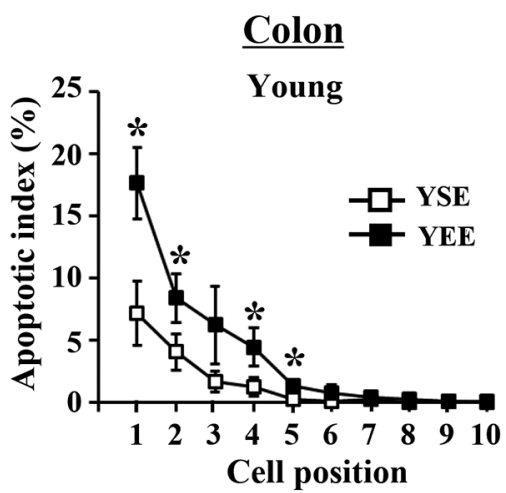

D

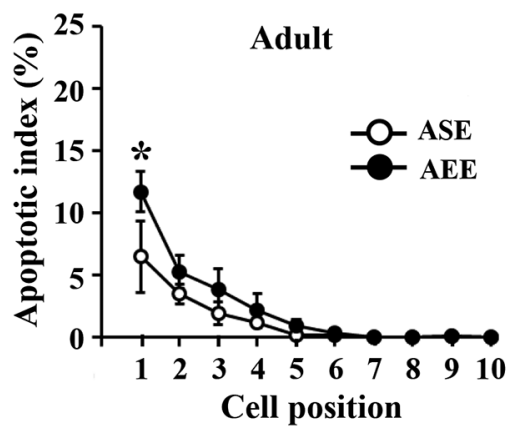

Figure 4. The distribution of apoptotic cells in the crypts of the small intestine and colon in young and adult irradiated mice. Young ( $Y$ ) or adult (A) mice were exposed to an enriched environment (EE) or a standard environment (SE) and then irradiated. (A-D) The apoptotic index (based on cleaved caspase 3 immunostaining) was determined for cells at each position in the small intestinal ( $A$ and $C)$ and colonic $(B$ and $D)$ crypts at $3 \mathrm{~h}$ after irradiation in young $(A$ and $B)$ and adult $(C$ and $D)$ mice. Data are shown as the mean $\pm S E(n=4$ or 5 mice per group). * $p<0.05$ for YSE vs. YEE or ASE vs. AEE.

young mice, an EE increased the percentage of apoptotic cells at cell positions 1-5 in the small intestine and colon (Figure 4A and B), with statistical significance in the latter. In adult mice, an EE significantly increased the percentage of apoptotic cells at cell position 1 in the colon (Figure 4D). These results suggest that an EE enhances radiation-induced apoptosis more effectively in the stem cells of the colon than in those of the small intestine.

\section{Discussion}

In the present study, we first characterized the effect of the EE condition established in our laboratory on the physiology of mice and confirmed its beneficial effects on body weight, lipid accumulation, and lipid metabolism in both young and adult mice, which is consistent with a previous report (31). We then clarified the modifying effects of an EE on spontaneous and radiation-induced apoptosis in the intestinal epithelium, showing for the first time that an EE enhances radiation-induced, but not spontaneous, apoptosis.

Studies on rodent models have reported that an EE prevents spontaneous apoptosis in the hippocampus of mice (6) but not in cardiac or renal tissues of male rats (10).
Compared to the present finding in the mouse intestine, the effects of an EE on spontaneous apoptosis may differ depending on the organ. Regarding organs after irradiation, a previous report indicated that an EE partially attenuates apoptosis in the hippocampus of mice after total-body irradiation at a much higher dose of $10 \mathrm{~Gy}$ (32). Moderate exercise, a key component of an EE, also prevents radiationinduced apoptosis in the bone marrow (17). In the present study, an EE enhanced radiation-induced apoptosis in the intestinal tract at a moderate dose of $2 \mathrm{~Gy}$, indicating the opposite effect in this tissue. Thus, an EE has different effects on radiation-induced apoptosis depending on the organ, as with spontaneous apoptosis.

We also observed that the effect of an EE on enhancement of radiation-induced apoptosis was strongest at cell positions 1-5 in the intestinal crypts. Previous reports have indicated that apoptotic cells in the small intestine and colon after irradiation are concentrated in the bottom of the crypt $(5,15$, 33 ), which is consistent with the present study. A variety of stem cells $\left(\mathrm{Lgr} 5^{+}\right.$stem cells at the crypt base and $\mathrm{Bmil}^{+}$and radiosensitive stem cells at higher positions) reside at positions 1-5 of the crypt, and the radiosensitivity of $\mathrm{Lgr}^{+}$ stem cells is higher than that of $\mathrm{Bmil}^{+}$stem cells $(34,35)$, 
indicating that an EE promotes radiation-induced apoptosis of these stem cells. As intestinal stem cells are a potential origin of intestinal cancer (36), the elimination of damaged stem cells through induction of apoptosis by an EE condition may contribute to preventing initiation of carcinogenesis. Thus, the potentially beneficial effects of an EE in non-CNS organs, as observed herein, are worth further investigation in the field of radiation biology, similar to those in the CNS including improvement of cognitive function and prevention of neural diseases. The dependence of such beneficial effects on tissue type (e.g., small intestine vs. colon) and the age of the organism will also be of interest, as suggested by the present study.

The different effects of an EE among tissues may be accounted for by differences in the regulation of pro- and anti-apoptotic factors. In the hypothalamus, an EE increases the synthesis of brain-derived neurotrophic factor, which stimulates proliferation and inhibits apoptosis of neuronal cells (6). Our study showed that an EE significantly decreased the serum levels of insulin and leptin. These hormones share downstream signaling pathways such as the mitogen-activated protein kinase pathway, the phosphatidylinositol 3-kinase (PI3K) pathway, and the Janus kinase (JAK)-signal transducer and activator of transcription pathway, all of which inhibit apoptosis (37-41). Indeed, deficiency in insulin receptor signaling is reported to increase radiation-induced apoptosis in the intestinal crypt stem cells $(18,42,43)$. Similarly, the anti-apoptotic function of leptin has been observed in a wide range of non-cancerous cells including placental cells, $\mathrm{T}$ lymphocytes, and pancreatic $\beta$ cells (44-46). The presence of the leptin receptor on the cell surface of enterocytes and colonocytes (47) suggests that leptin signals contribute to apoptosis of intestinal cells. Based on the above, our EE condition could have enhanced the radiation-induced apoptosis through down-regulation of PI3K and JAK signaling via a decrease in serum leptin levels. On the other hand, EE did not affect spontaneous apoptosis. The induction mechanism of spontaneous apoptosis is different from radiation-induced apoptosis (48). The spontaneous apoptosis is a normal homeostatic process, which is regulated by the 53-independent pathway, whereas the acute apoptosis induction by radiation exposure is controlled by the p53-dependendent pathway. Hence it could be considered that EE had an enhancing effect only on the p53-dependent apoptosis induction.

In contrast, although IL- 6 and MCP1 have anti-apoptotic functions in the intestinal epithelium $(49,50)$, our EE condition did not change the serum level of these inflammatory cytokines, indicating that the effects of our EE on apoptosis induction is unlikely to be associated with these cytokines.

In conclusion, we characterized the effects of the present EE condition and found for the first time that an EE enhances susceptibility to radiation-induced apoptosis of stem cells in the small intestine and colon without affecting spontaneous apoptosis. It is, therefore, implied that EE promoted the elimination of DNA damaged cells by inducing apoptosis after radiation exposure. Hence an EE may reduce the risk of cancer in the intestinal tract after radiation exposure such as radiotherapy.

\section{Funding}

This work was supported by the Ministry of Education, Culture, Sports, Science and Technology of Japan via the Nuclear Energy Science and Technology and Human Resource Development Project through Concentrating Wisdom (No. 271301).

\section{Conflicts of Interest}

The Authors declare that they have no conflicts of interest.

\section{Authors' Contributions}

SY, MN, TM, and YS designed the experiments. SY, MN, TM, UE, CT, YS, YN, and YS performed the animal experiments. SY and TM performed the histopathological and immunohistochemical analyses. SY and MN analysed the data. YS and TM contributed to the acquisition of funding. SY, MN, TM, SK, KI, MF, and YS prepared the initial draft of the manuscript. SY, TM, TI, SK, and YS finalized the manuscript. All Authors reviewed and approved the final manuscript.

\section{Acknowledgements}

We thank Dr. Shunsuke Yamazaki, Ms. Mutsumi Kaminishi, Ms. Ayako Otsuka, and Ms. Mayumi Okabe for animal care and experimentation. We are also very thankful to all members of the Laboratory Animal and Genome Science Section, NIRS, QST for help with animal maintenance.

\section{References}

1 Sztainberg Y and Chen A: An environmental enrichment model for mice. Nat Protoc 5(9): 1535-1539, 2010. PMID: 20725068. DOI: $10.1038 /$ nprot.2010.114

2 Nithianantharajah $\mathrm{J}$ and Hannan AJ: Enriched environments, experience-dependent plasticity and disorders of the nervous system. Nat Rev Neurosci 7(9): 697-709, 2006. PMID: 16924259. DOI: $10.1038 / \mathrm{nrn} 1970$

3 Cao L and During MJ: What is the brain-cancer connection? Annu Rev Neurosci 35: 331-345, 2012. PMID: 22462541. DOI: 10.1146/annurev-neuro-062111-150546

4 Cheng L, Wang SH, Jia N, Xie M and Liao XM: Environmental stimulation influence the cognition of developing mice by inducing changes in oxidative and apoptosis status. Brain Dev 36(1): 51-56, 2014. PMID: 23273784. DOI: 10.1016/ j.braindev.2012.11.015

5 Marshman E, Ottewell PD, Potten CS and Watson AJ: Caspase activation during spontaneous and radiation-induced apoptosis in the murine intestine. J Pathol 195(3): 285-292, 2001. PMID: 11673824. DOI: $10.1002 /$ path.967 
6 Young D, Lawlor PA, Leone P, Dragunow M and During MJ: Environmental enrichment inhibits spontaneous apoptosis, prevents seizures and is neuroprotective. Nat Med 5(4): 448-453, 1999. PMID: 10202938. DOI: 10.1038/7449

7 Zhao Y, Chen $\mathrm{K}$ and Shen X: Environmental enrichment attenuated sevoflurane-induced neurotoxicity through the PPAR$\gamma$ signaling pathway. Biomed Res Int 2015: 107149, 2015. PMID: 26236713. DOI: 10.1155/2015/107149

8 Wang Q, Shen FY, Zou R, Zheng JJ, Yu X and Wang YW: Ketamine-induced apoptosis in the mouse cerebral cortex follows similar characteristic of physiological apoptosis and can be regulated by neuronal activity. Mol Brain 10(1): 24, 2017. PMID: 28623920. DOI: 10.1186/s13041-017-0302-2

9 Salmin VV, Komleva YK, Kuvacheva NV, Morgun AV, Khilazheva ED, Lopatina OL, Pozhilenkova EA, Shapovalov KA, Uspenskaya YA and Salmina AB: Differential roles of environmental enrichment in Alzheimer's type of neurodegeneration and physiological aging. Front Aging Neurosci 9: 245, 2017. PMID: 28798684. DOI: 10.3389/ fnagi.2017.00245

10 Li X, Li S, Zheng W, Pan J, Huang K, Chen R, Pan T, Liao G, Chen Z, Zhou D, Shen W, Zhou W and Liu Y: Environmental enrichment and abstinence attenuate ketamine-induced cardiac and renal toxicity. Sci Rep 5: 11611, 2015. PMID: 26112338. DOI: $10.1038 /$ srep11611

11 Pejchal J, Novotný J, Mařák V, Osterreicher J, Tichý A, Vávrová J, Sinkorová Z, Zárybnická L, Novotná E, Chládek J, Babicová A, Kubelková K and Kuča K: Activation of p38 MAPK and expression of TGF- $\beta 1$ in rat colon enterocytes after whole body $\gamma$-irradiation. Int J Radiat Biol 88(4): 348-358, 2012. PMID: 22233094. DOI: 10.3109/09553002.2012.654044

12 Almasan A: Cellular commitment to radiation-induced apoptosis. Radiat Res 153(3): 347-350, 2000. PMID: 10669558. DOI: 10.1667/0033-7587(2000)153[0347:cctria]2.0.co;2

13 Otsuka K and Suzuki K: Differences in radiation dose response between small and large intestinal crypts. Radiat Res 186(3): 302-314, 2016. PMID: 27556352. DOI: 10.1667/RR14455.1

14 Potten CS and Grant HK: The relationship between ionizing radiation-induced apoptosis and stem cells in the small and large intestine. Br J Cancer 78(8): 993-1003, 1998. PMID: 9792141. DOI: $10.1038 /$ bjc. 1998.618

15 Miyoshi-Imamura T, Kakinuma S, Kaminishi M, Okamoto M, Takabatake T, Nishimura Y, Imaoka T, Nishimura M, MurakamiMurofushi $\mathrm{K}$ and Shimada Y: Unique characteristics of radiation-induced apoptosis in the postnatally developing small intestine and colon of mice. Radiat Res 173(3): 310-318, 2010. PMID: 20199216. DOI: 10.1667/RR1905.1

16 Feng Z, Liu L, Zhang C, Zheng T, Wang J, Lin M, Zhao Y, Wang $\mathrm{X}$, Levine $\mathrm{AJ}$ and $\mathrm{Hu} \mathrm{W}$ : Chronic restraint stress attenuates p53 function and promotes tumorigenesis. Proc Natl Acad Sci U.S.A. 109(18): 7013-7018, 2012. PMID: 22509031. DOI: $10.1073 /$ pnas.1203930109

17 De Lisio M, Phan N, Boreham DR and Parise G: Exerciseinduced protection of bone marrow cells following exposure to radiation. Appl Physiol Nutr Metab 36(1): 80-87, 2011. PMID: 21326381. DOI: 10.1139/H10-087

18 Santoro MA, Blue RE, Andres SF, Mah AT, Van Landeghem L and Lund PK: Obesity and intestinal epithelial deletion of the insulin receptor, but not the IGF 1 receptor, affect radiationinduced apoptosis in colon. Am J Physiol Gastrointest Liver
Physiol 309(7): G578-G589, 2015. PMID: 26251471. DOI: 10.1152/ajpgi.00189.2015

19 Paban V, Chambon C, Manrique C, Touzet C and AlescioLautier B: Neurotrophic signaling molecules associated with cholinergic damage in young and aged rats: environmental enrichment as potential therapeutic agent. Neurobiol Aging 32(3): 470-485, 2011. PMID: 19398249. DOI: 10.1016/ j.neurobiolaging 2009.03 .010

20 Mainardi M, Scabia G, Vottari T, Santini F, Pinchera A, Maffei L, Pizzorusso $\mathrm{T}$ and Maffei $\mathrm{M}$ : A sensitive period for environmental regulation of eating behavior and leptin sensitivity. Proc Natl Acad Sci U.S.A. 107(38): 16673-16678, 2010. PMID: 20823242. DOI: 10.1073/pnas.0911832107

21 Otaki M, Hirano T, Yamaguchi Y, Kaida K, Koshika S, Nagata K, Nishimura M, Kakinuma S, Shimada Y and Kobayashi Y: Changes in the function and phenotype of resident peritoneal macrophages after housing in an enriched environment. Int Immunopharmacol 65: 44-49, 2018. PMID: 30273916. DOI: 10.1016/j.intimp.2018.09.037

22 Sakama S, Kurusu K, Morita M, Oizumi T, Masugata S, Oka S, Yokomizo S, Nishimura M, Morioka T, Kakinuma S, Shimada $\mathrm{Y}$ and Nakamura AJ: An enriched environment alters DNA repair and inflammatory responses after radiation exposure. Front Immunol 12: 760322, 2021. PMID: 34745135. DOI: 10.3389/fimmu.2021.760322

23 Morioka T, Blyth BJ, Imaoka T, Nishimura M, Takeshita H, Shimomura T, Ohtake J, Ishida A, Schofield P, Grosche B, Kulka U, Shimada Y, Yamada Y and Kakinuma S: Establishing the Japan-Store house of animal radiobiology experiments (JSHARE), a large-scale necropsy and histopathology archive providing international access to important radiobiology data. Int J Radiat Biol 95(10): 1372-1377, 2019. PMID: 31145030. DOI: $10.1080 / 09553002.2019 .1625458$

24 Cao L, Choi EY, Liu X, Martin A, Wang C, Xu X and During MJ: White to brown fat phenotypic switch induced by genetic and environmental activation of a hypothalamic-adipocyte axis. Cell Metab 14(3): 324-338, 2011. PMID: 21907139. DOI: 10.1016/j.cmet.2011.06.020

25 Rogozina OP, Bonorden MJ, Seppanen CN, Grande JP and Cleary MP: Effect of chronic and intermittent calorie restriction on serum adiponectin and leptin and mammary tumorigenesis. Cancer Prev Res (Phila) 4(4): 568-581, 2011. PMID: 21257708. DOI: 10.1158/1940-6207.CAPR-10-0140

26 Mainardi M, Pizzorusso T and Maffei M: Environment, leptin sensitivity, and hypothalamic plasticity. Neural Plast 2013: 438072, 2013. PMID: 23970977. DOI: $10.1155 / 2013 / 438072$

27 Nachat-Kappes R, Pinel A, Combe K, Lamas B, Farges MC, Rossary A, Goncalves-Mendes N, Caldefie-Chezet F, Vasson MP and Basu S: Effects of enriched environment on COX-2, leptin and eicosanoids in a mouse model of breast cancer. PLoS One 7(12): e51525, 2012. PMID: 23272114. DOI: 10.1371/journal. pone. 0051525

28 Jurgens HA and Johnson RW: Environmental enrichment attenuates hippocampal neuroinflammation and improves cognitive function during influenza infection. Brain Behav Immun 26(6): 1006-1016, 2012. PMID: 22687335. DOI: 10.1016/j.bbi.2012.05.015

29 Brod S, Gobbetti T, Gittens B, Ono M, Perretti M and D'Acquisto F: The impact of environmental enrichment on the murine inflammatory immune response. JCI Insight 2(7): 
e90723, 2017. PMID: 28405616. DOI: 10.1172/jci.insight. 90723

30 Pritchard DM, Print C, O'Reilly L, Adams JM, Potten CS and Hickman JA: Bcl-w is an important determinant of damageinduced apoptosis in epithelia of small and large intestine. Oncogene 19(34): 3955-3959, 2000. PMID: 10951589. DOI: 10.1038/sj.onc.1203729

31 Xu L, Jiao M, Cui ZL, Zhao QY, Wang Y, Chen S, Zhang JJ, Jin $\mathrm{YH}, \mathrm{Mu} \mathrm{D}$ and Yang YQ: Enriched environment during adolescence modulates lipid metabolism and emotion-related behaviors in mice. J Appl Anim Welf Sci: 1-11, 2021. PMID: 34470518. DOI: 10.1080/10888705.2021.1972421

32 Ruitenberg MJ, Wells J, Bartlett PF, Harvey AR and Vukovic J: Enrichment increases hippocampal neurogenesis independent of blood monocyte-derived microglia presence following high-dose total body irradiation. Brain Res Bull 132: 150-159, 2017. PMID: 28552674. DOI: 10.1016/j.brainresbull.2017.05.013

33 Potten CS, Merritt A, Hickman J, Hall P and Faranda A: Characterization of radiation-induced apoptosis in the small intestine and its biological implications. Int J Radiat Biol 65(1): 71-78, 1994. PMID: 7905913. DOI: 10.1080/09553009 414550101

34 Metcalfe C, Kljavin NM, Ybarra R and de Sauvage FJ: Lgr5+ stem cells are indispensable for radiation-induced intestinal regeneration. Cell Stem Cell 14(2): 149-159, 2014. PMID: 24332836. DOI: 10.1016/j.stem.2013.11.008

35 Yan KS, Chia LA, Li X, Ootani A, Su J, Lee JY, Su N, Luo Y, Heilshorn SC, Amieva MR, Sangiorgi E, Capecchi MR and Kuo CJ: The intestinal stem cell markers Bmi1 and Lgr5 identify two functionally distinct populations. Proc Natl Acad Sci U S A 109(2): 466-471, 2012. PMID: 22190486. DOI: 10.1073/ pnas.1118857109

36 Zhang $\mathrm{Z}$ and Huang J: Intestinal stem cells - types and markers. Cell Biol Int 37(5): 406-414, 2013. PMID: 23471862. DOI: 10.1002/cbin.10049

37 Teng JA, Wu SG, Chen JX, Li Q, Peng F, Zhu Z, Qin J and He ZY: The activation of ERK1/2 and JNK MAPK signaling by Insulin/IGF-1 is responsible for the development of colon cancer with type 2 diabetes mellitus. PLoS One 11(2): e0149822, 2016. PMID: 26901856. DOI: 10.1371/journal.pone.0149822

38 Qiu W, Leibowitz B, Zhang L and Yu J: Growth factors protect intestinal stem cells from radiation-induced apoptosis by suppressing PUMA through the PI3K/AKT/p53 axis. Oncogene 29(11): 1622-1632, 2010. PMID: 19966853. DOI: 10.1038/ onc. 2009.451

39 Pérez-Pérez A, Maymó J, Dueñas JL, Goberna R, Calvo JC, Varone C and Sánchez-Margalet V: Leptin prevents apoptosis of trophoblastic cells by activation of MAPK pathway. Arch Biochem Biophys 477(2): 390-395, 2008. PMID: 18619412. DOI: $10.1016 /$ j.abb.2008.06.015

40 Lawrence JE, Cook NJ, Rovin RA and Winn RJ: Leptin promotes glioblastoma. Neurol Res Int 2012: 870807, 2012. PMID: 22263109. DOI: 10.1155/2012/870807

41 Wang D, Chen J, Chen H, Duan Z, Xu Q, Wei M, Wang L and Zhong M: Leptin regulates proliferation and apoptosis of colorectal carcinoma through PI3K/Akt/mTOR signalling pathway. J Biosci 37(1): 91-101, 2012. PMID: 22357207. DOI: 10.1007/s12038-011-9172-4
42 Otsuka $\mathrm{K}$ and Iwasaki T: Effects of dose rates on radiationinduced replenishment of intestinal stem cells determined by Lgr5 lineage tracing. J Radiat Res 56(4): 615-622, 2015. PMID: 25832104. DOI: $10.1093 / \mathrm{jrr} / \mathrm{rrv} 012$

43 Ramocki NM, Wilkins HR, Magness ST, Simmons JG, Scull BP, Lee GH, McNaughton KK and Lund PK: Insulin receptor substrate-1 deficiency promotes apoptosis in the putative intestinal crypt stem cell region, limits Apcmin/+ tumors, and regulates Sox9. Endocrinology 149(1): 261-267, 2008. PMID: 17916629. DOI: 10.1210/en.2007-0869

44 Fujita Y, Murakami M, Ogawa Y, Masuzaki H, Tanaka M, Ozaki $\mathrm{S}$, Nakao $\mathrm{K}$ and Mimori T: Leptin inhibits stress-induced apoptosis of T lymphocytes. Clin Exp Immunol 128(1): 21-26, 2002. PMID: 11982586. DOI: 10.1046/j.1365-2249.2002. 01797.x

45 Toro AR, Maymó JL, Ibarbalz FM, Pérez-Pérez A, Maskin B, Faletti AG, Sánchez-Margalet V and Varone CL: Leptin is an anti-apoptotic effector in placental cells involving p53 downregulation. PLoS One 9(6): e99187, 2014. PMID: 24922063. DOI: 10.1371/journal.pone.0099187

46 Shimabukuro M, Wang MY, Zhou YT, Newgard CB and Unger RH: Protection against lipoapoptosis of beta cells through leptindependent maintenance of Bcl-2 expression. Proc Natl Acad Sci U.S.A. 95(16): 9558-9561, 1998. PMID: 9689119. DOI: 10.1073/pnas.95.16.9558

47 Hansen GH, Niels-Christiansen LL and Danielsen EM: Leptin and the obesity receptor (OB-R) in the small intestine and colon: a colocalization study. J Histochem Cytochem 56(7): 677-685, 2008. PMID: 18413648. DOI: 10.1369/jhc.2008.950782

48 Watson AJ and Pritchard DM: Lessons from genetically engineered animal models. VII. Apoptosis in intestinal epithelium: lessons from transgenic and knockout mice. Am J Physiol Gastrointest Liver Physiol 278(1): G1-G5, 2000. PMID: 10644554. DOI: 10.1152/ajpgi.2000.278.1.G1

49 Grivennikov S, Karin E, Terzic J, Mucida D, Yu GY, Vallabhapurapu S, Scheller J, Rose-John S, Cheroutre H, Eckmann L and Karin M: IL-6 and Stat3 are required for survival of intestinal epithelial cells and development of colitisassociated cancer. Cancer Cell 15(2): 103-113, 2009. PMID: 19185845. DOI: 10.1016/j.ccr.2009.01.001

50 McClellan JL, Davis JM, Steiner JL, Enos RT, Jung SH, Carson JA, Pena MM, Carnevale KA, Berger FG and Murphy EA: Linking tumor-associated macrophages, inflammation, and intestinal tumorigenesis: role of MCP-1. Am J Physiol Gastrointest Liver Physiol 303(10): G1087-G1095, 2012. PMID: 23019193. DOI: 10.1152 /ajpgi.00252.2012
Received November 10, 2021

Revised December 3, 2021

Accepted December 15, 2021 